\title{
National electronic disease surveillance: a dream delayed
}

A fter the SARS disaster killed 44 people in Ontario in 2003 , the federal government was advised by an expert panel to bolster a "system that will collect, analyze, and disseminate laboratory and health care facility data on infectious diseases and noninfectious diseases" while also extending "the business processes for infectious disease surveillance."

To help get this monumental job done, the panel, led by Dr. David Naylor, the then-dean of medicine at the University of Toronto in Ontario, suggested Ottawa invest in electronic information systems "to enhance disease surveillance and link public health and clinical information systems."

Ten years later, many observers give Ottawa substantial credit for extending national disease surveillance capacity, but progress has been achingly slow on developing a national electronic surveillance system, they lament.

Ottawa's initial response to the Naylor panel's call for a national electronic surveillance system was swift and generous. In March 2004, the federal government provided $\$ 100$ million (increased to $\$ 135$ million in 2007) to support the development of a pan-Canadian health surveillance system to Canada Health Infoway, a Crown corporation created in 2001 to create a national electronic health "infostructure."

Infoway forged a collaboration with the British Columbia Ministry of Health and selected IBM to create the system, which was dubbed Panorama. IBM completed the design in 2008 and, according to the initial contract, development and implementation of the system was to be completed by 2009. But according to an audit of the project published that year, progress was delayed by numerous technical problems and confusion among the provinces — a pattern remarkably similar to the confusion and delays with Infoway's broader efforts to create the national infostructure.
Since then, little has been seen or heard of Panorama, says Dr. Tom Noseworthy, professor of health policy and management in the Department of Community Health Sciences at the University of Calgary in Alberta.

"The concept has gone almost nowhere," he says, while noting that Alberta opted out of Infoway's surveillance plan from the outset.

Dr. Vivek Goel, president and CEO of the Ontario Public Health Agency, offers a more optimistic view. Despite years of delay, due largely to jurisdictional and political barriers, some parts of the Panorama system could begin functioning in Ontario in 2014, he believes, in large part because BC's efforts to create the system are now at least starting to take a concrete form that other provinces can assess.

BC Ministry of Health spokeswoman Laura Neufeld says BC has been reimbursed $\$ 47.8$ million for leading the development of Panorama.

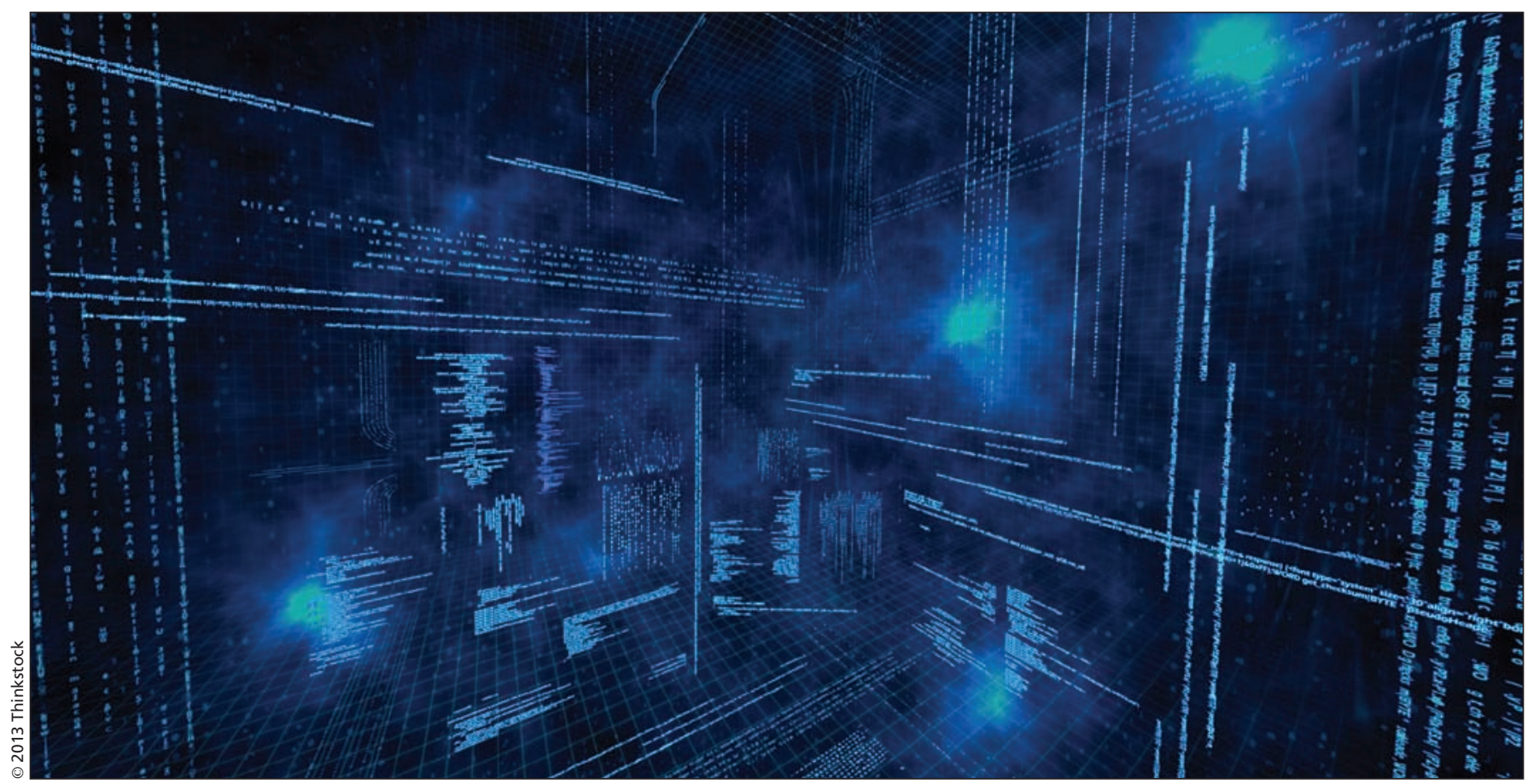

The hugely complex pan-Canadian surveillance system is in various phases across multiple jurisdictions. 
$\mathrm{BC}$ will soon implement immunization and family health components of the system, she adds, and "the final two Panorama modules - Investigations and Outbreak Management - are scheduled for release across the province a year from now."

Outside of BC, she adds "product delivery is in various phases across multiple jurisdictions in support of the national vision of standardized public health reporting." The system is a "public health care application" she says that will be used in public health and First Nations community clinics outside hospitals. "While deployment to hospitals is not part of the strategy at this time, it is possible if the business need arises to deploy Panorama in an acute care environment to support outbreak management," she adds.

Goel and Noseworthy say they worry that Infoway's decade-old tech- nological framework for Panorama may have been overtaken by rapid technological changes.

This is a point strongly emphasized by a contractor working on the Panorama project in Toronto who spoke to $C M A J$ on the basis of confidentiality. "The fundamental problem with Panorama has been that Infoway insisted on integrating it into its overall master plan, which has turned out to be disastrously overly complex and unsuited to quickly meeting public health needs."

"We're now looking towards a world where people are working with tablets," Goel notes, "and we're going to see some very disruptive innovations." At IBM Canada Ltd., Leslie Plant, external communications manager, notes that technical details regarding the Panorama system have been published on the IBM website (www-03.ibm .com/industries/ca/en/healthcare/files /panorama_application_overview_final .pdf and www-03.ibm.com/industries /ca/en/healthcare/solutions.html).

Beyond that, Plant says "IBM has no further current public information about Panorama available" and added that "Infoway really is the best source of information about where the project is today."

For its part, Infoway did not respond to requests for interviews. A 2007 article on the Infoway website notes that SARS proved the need for Panorama to address "a really glaring example of a failure in the system" (http://v1.theglobeandmail.com/partners /free/infoway/article_sars.html).

More recent postings about Panorama on the Infoway site are now inactive. - Paul Webster, Toronto, Ont.

CMAJ 2013. DOI:10.1503/cmaj.109-4450 